\title{
RAMAYANA EPISODES IN HIMACHAL PAINTINGS: THE LEIDEN COLLECTION
}

As it has been throughout the ages elsewhere in South and South-East Asia, Ramayana, the famous epic extolling the heroic acts of the 'ideal' King Rama, also enjoyed quite some popularity among the masses in a large tract of the Western Himalayan foothills. ${ }^{1}$ Nowhere in this region is it more tangible than in the miniature paintings of the former Punjab Hill States, now known as Himachal Pradesh in India. From the $17^{\text {th }}$ to the $19^{\text {th }}$ century, painting was a common enough accomplishment in the majority of the principalities between Basohli in the west to Kulu in the east. Most notable among them were Kangra and Chamba where well-known episodes from the Rama epic received much attention of skillful court artists and their devout patrons.

Among the modest holding of Indian Art in the Museum Volkenkunde (National Museum of Ethnology) in Leiden there is an as yet little-known group of Ramayana illustrations of Chamba-Kangra origin. These miniatures form a substantial part of the 'Vogel Collection' which was acquired by the museum nearly half a century ago. ${ }^{2}$ During his prolonged stay in India the outstanding Dutch scholar, J.Ph. Vogel (1871-1958), made several trips to both Chamba and Kangra. While doing his extensive 1902-1908 archaeological fieldwork in the Ravi and Beas valleys, Vogel was able to collect pieces for which people at that time cared very little. ${ }^{3}$

The Ramayana illustrations in the museum consist of 21 leaves. Other than a rather exceptional example which is indeed embellished with multiple colours, the rest are virtually all monochrome line-drawings. The figures and motifs are drawn with red outlines in some instances and with grayish-black in others. A close study of the material shows that they belonged to more than just one manuscript of the epic. Unfortunately, the majority of them are damaged due to human negligence in the past. However, in this paper we shall briefly deal with just five select examples.

One of the finest sketches in the series depicts Rama successfully handling the bow at the court of King Janaka of Mithila and thereby winning Sita (fig. 1). ${ }^{4}$ Although only drawn, the representation presents a good view of the palace of Janaka. Standing in heroic pose, Rama is stretching his bow in the middle of the palace courtyard. Apart from Laksmana, others present in the scene are Sita with royal ladies, sage Visvamitra accompanied by some ascetics and a group of musicians in the foreground. The great event is eagerly watched by King Janaka and several dignitaries from the pavilion overlooking the open courtyard. It is a remarkable composition where all the activities are arranged round the central figure of Rama. 


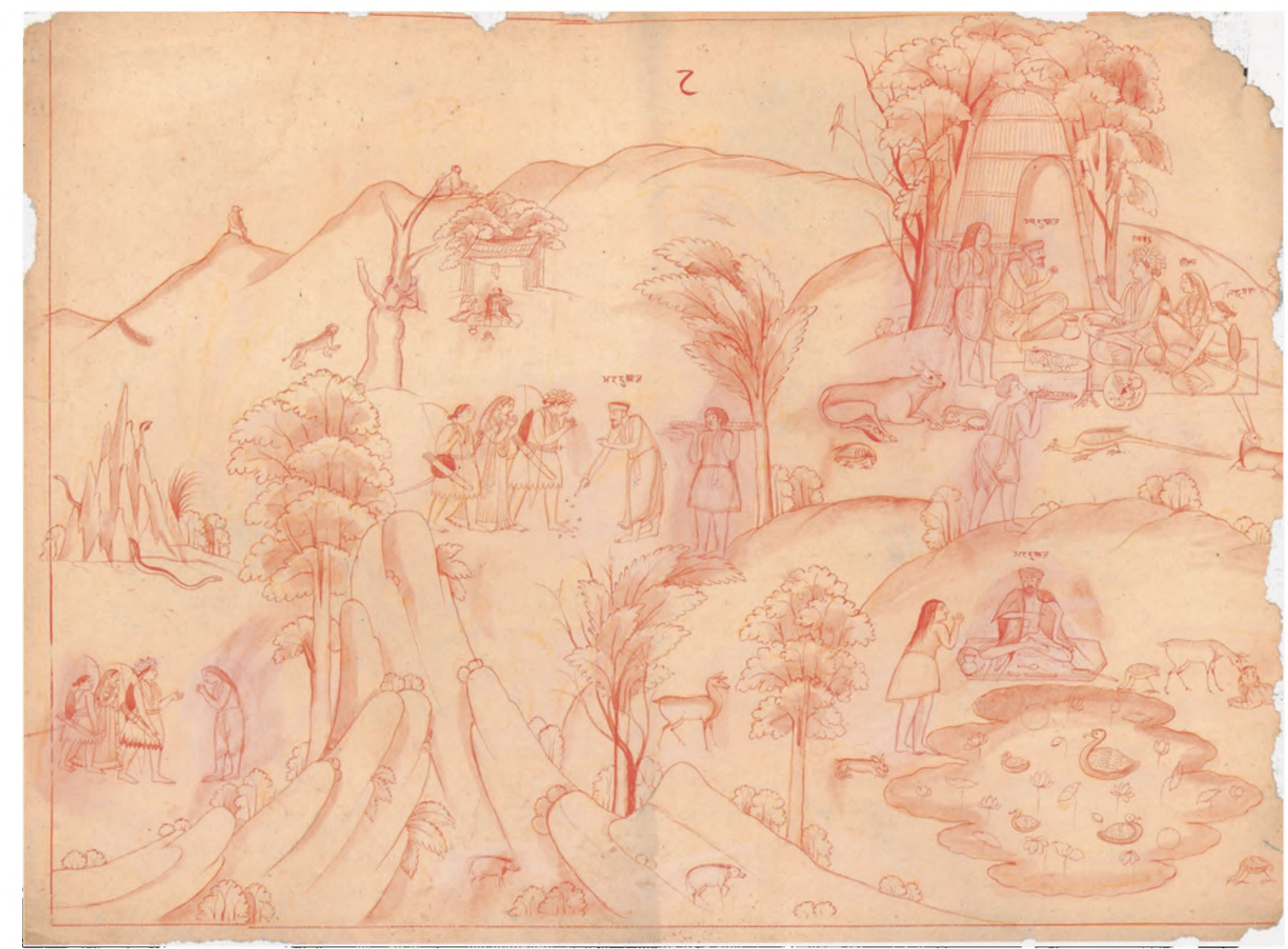

Figure 2

Sage Bharadvaja's hermitage near Prayag, parchment, $28.6 \times 40$ cm., Chamba, 1790 1800 , Museum Volkenkunde, 3025-15
The serene atmosphere of the hermitage in a mountainous surrounding is graphically illustrated in a red-lined miniature depicting the dwelling of the sage Bharadvaja (fig. 2). According to the story, Rama, Laksmana and Sita, on their way to the Chitrakuta mountain, stayed in Bharadvaja's place, not far from the confluence of the rivers Ganges and the Yamuna. Interestingly, in this example both Rama and Laksmana are shown attired in skirts made of leaves; but Rama, in addition, is also wearing a headdress made of protruding foliage.

The inconsolable grief of the womenfolk as well as of the monkeys is graphically rendered in a drawing (fig. 3), showing the death of Vali, the elder brother of Sugriva, the monkey king of Kishkindhya, and his cremation in the mountainous surroundings of Kishkindhya. Although partly water-soaked and considerably damaged, the main body of the picture remains still intact. One finds here the final end of Vali, as Rama's arrow pierced through his chest. Following the sequence of depiction we find in the vicinity a stretcher, kept ready for the conveyance of Vali's body. Thereafter he is shown being carried to the funeral pyre indicated by flames of fire at the top right end of the frame. In the diagonally opposite corner Rama is blessing Sugriva while Laksmana and Hanuman watch the event with rapt attention. Curiously, an incomplete sketch in the top left corner shows Vali being transported on a couch by the monkeys. It probably indicates the monkey chief's journey to heaven after his mortal demise in this world. 
A beautiful, partly coloured drawing illustrates Laksmana meeting Sugriva to remind him of his promise to help Rama in finding Sita (fig. 4). The illustration includes a part of the palace at Kishkindhya and the queens seated

Figure 3

Death of Vali and his cremation, parchment, $28.2 \times 23.5 \mathrm{~cm}$, Chamba, 1810-1820, Museum Volkenkunde, 3025-3 therein. The restless monkeys are shown almost everywhere amidst the jutting rocks. In the lower part of the scene Laksmana and Hanuman are engaged in deep conversation.

The best-preserved, fully coloured illustration in the collection depicts the hermitage of Agastya (fig. 5) in the Vindhyan mountain. According to the text Rama received several weapons from the sage, including a bow and a quiver full of arrows. The flowering trees, the lotus pond, the bucks and the birds as well as the assemblage of a few ascetics provide one with a good impression of the abode of the sage.

Although these illustrated pages are not from one single manuscript, the artists followed a uniform method and technique of production. The drawings are done on a special type of parchment known as Sialkoti paper. These are handmade and usually yellowish in colour. The figures are outlined either in greyish-black (fig. 1) or in light-red colour (fig. 2). Sometimes patches of thin wash of white paints can be detected on the figures, or on parts of the buildings (fig. 1). The translucent layers left the outlines sufficiently visible for the artist to make changes, if and when necessary. 


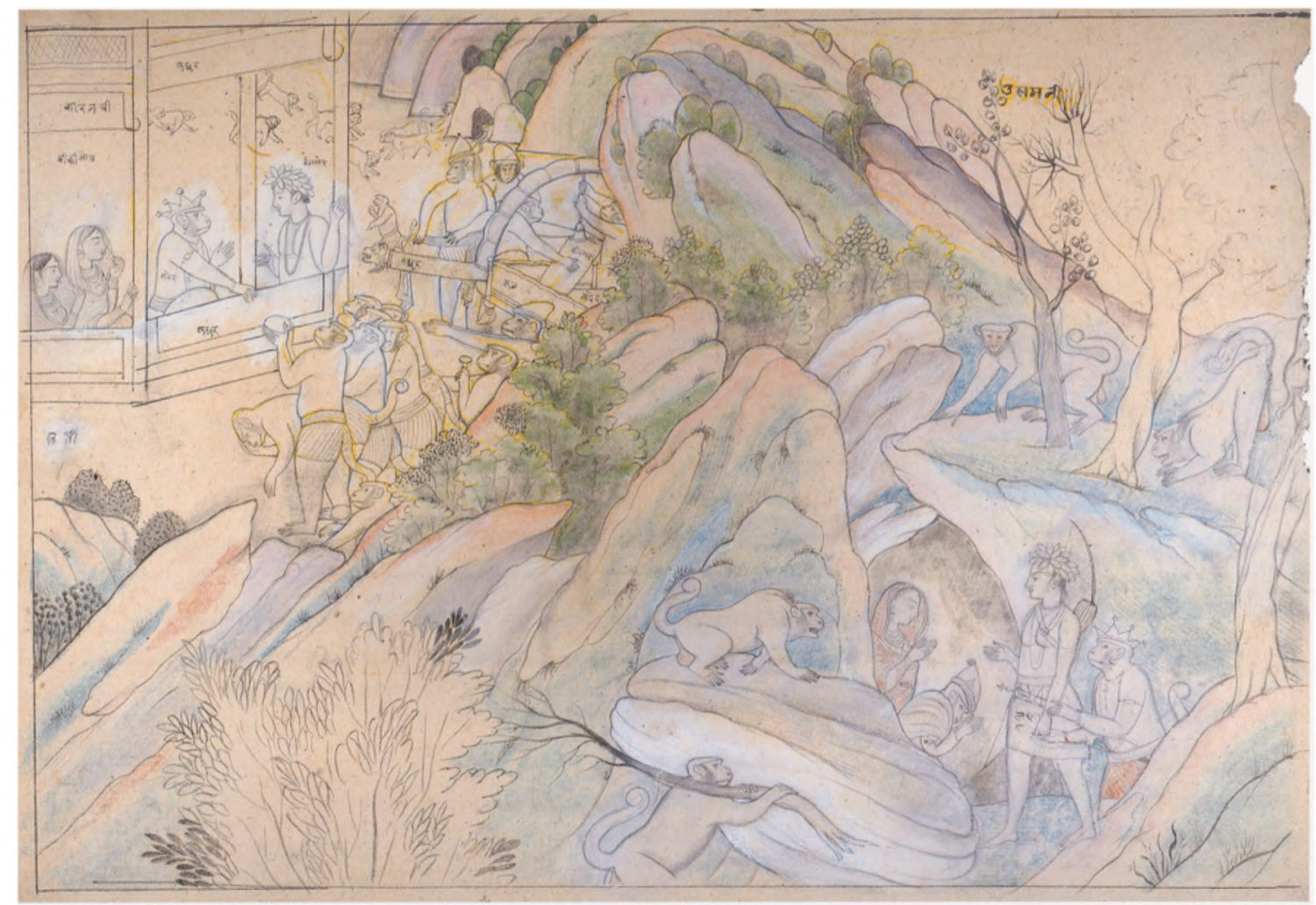

\section{Figure 4}

Laksmana meeting

Sugriva, parchment, $30.6 \times 20.9 \mathrm{~cm}$. Chamba, 1820-1820, Museum Volkenkunde, $3025-6$
Many of the pages contain serial numbers set forth mostly in Devanagari ciphers (fig. 3). While names of important personages written in Takri characters appear on the red-lined drawings (fig. 2), the grey-lined sketches are inscribed with the names of colours to be applied (fig. 1). Thus the words asmani (sky blue), sabji (vegetable green), gulabi (rose), sindur (vermilion red) and so forth are written in the usual Takri script. ${ }^{5}$

It seems that the master artist made drawings and indicated the colour keys. Afterwards the apprentice was asked to put on the pigments and finish the painting. Colours were customarily applied first on the background and then on the figures. More often than not, the outlined, half-finished pictures were made in advance, preserved for some years and completed - possibly with some modifications - as and when commissioned.

A close survey of the miniatures reveals that they are not only done with great care and attention but also with considerable artistic skill. Neatly organized, some of the works are rich in the command of fluid lines. This is best seen in Rama's participation in the archery contest at Mithila (fig. 1). As in most other examples in the collection, we miss here the brilliancy of colour, but that is partly compensated by the soft and refined treatment of the composition as a whole. Shown with their faces in profile, the long-limbed women represent the concept of feminine beauty and grace prevalent in the time and region.

Similar in style, but admittedly less lyrical than the previous example, is the sketch illustrating the death of Vali (fig. 3). An air of intense grief pervades the scene. The monkeys are treated sympathetically and they are showin ${ }^{08: 00: 35 \mathrm{AM}}$ 
invested with human traits. The landscape is dominated by long ranges of hills in the background. The usual formation of the jagged rocks skilfully indicates a cave in the foreground. In this work the artist achieved admirable balance in handling the series of motifs and events in an orderly manner.

The stylistic norm followed in the depiction of the death of Vali is carried on in the composition of Sugriva's encounter with Laksmana at Kishkindhya (fig. 4). Interestingly, an almost exact replica of this scene happens to be a fully coloured painting in the collection of the National Museum, New Delhi. ${ }^{6}$ As we have already pointed out, most of the Ramayana scenes in the Leiden collection are actually preliminary drawings, meant to be turned into finished works such as the one in New Delhi.

Although the Ramayana miniatures in the Leiden collection do not make a strictly homogeneous group, stylistically they are not far removed from one another. In order to know their possible date of creation, it may be useful to cast a further look into the formal and aesthetic qualities of the miniatures themselves. In doing so one can gain some insight from a comparative study of this material with others from the same area, now in different collections.

The tranquil grace and serene beauty lyrically expressed in the scene portraying Rama with the bow (fig. 1), recalls those qualities in the NalaDamayanti paintings - one of the finest achievements of the Kangra artists of the late $18^{\text {th }}$ to early $19^{\text {th }}$ century - now in the Museum of Fine Arts in Boston. ${ }^{7}$ Not only the subtle and refined figural forms, but also the architectural elements in our example bear a close resemblance to those in the Boston collection. As such, the drawing can be safely dated to more or less the same period, or perhaps better to between 1790 and 1800 .

The stylistic norm thus outlined seems to have been passed on to the next two of our examples: a) the cremation of Vali and b) Laksmana's encounter with Sugriva (figs. 3 and 4). Relatively harder in treatment than the work in Figure 1, both these pages - probably from a single manuscript - are noteworthy for the vividness of the details. Compared to the same episode in a Kangra miniature of circa 1825, the intense grief and sorrow are more effectively expressed here in figure $3 .^{8}$

Equally noteworthy is the spectacular formation of the rocks in Figure 4 . The hill artists' love of mountainous landscape is expressed often enough in the paintings of the $19^{\text {th }}$ century. This is also the time when rocks and boulders are shown in all conceivable shapes and forms. A series of hills dominate the far horizon in both of our drawings. Both these miniatures can be dated to between 1810 and 1820 .

The red-lined drawing (fig. 2) is equally rich in narrative details. Evidently from another Ramayana manuscript, it seems to be a class apart. The artist's love for mountainous landscape is more obvious here. Accustomed to his native Himalayan surroundings, the artist has drawn for the abode of the sage Bharadvaja at Prayaga a similar landscape: rather unrealistic for the Gangetic plain. Compared to the same episode in a Kangra miniature, the story here is told in greater detail, but in a less compact manner. ${ }^{9}$ 


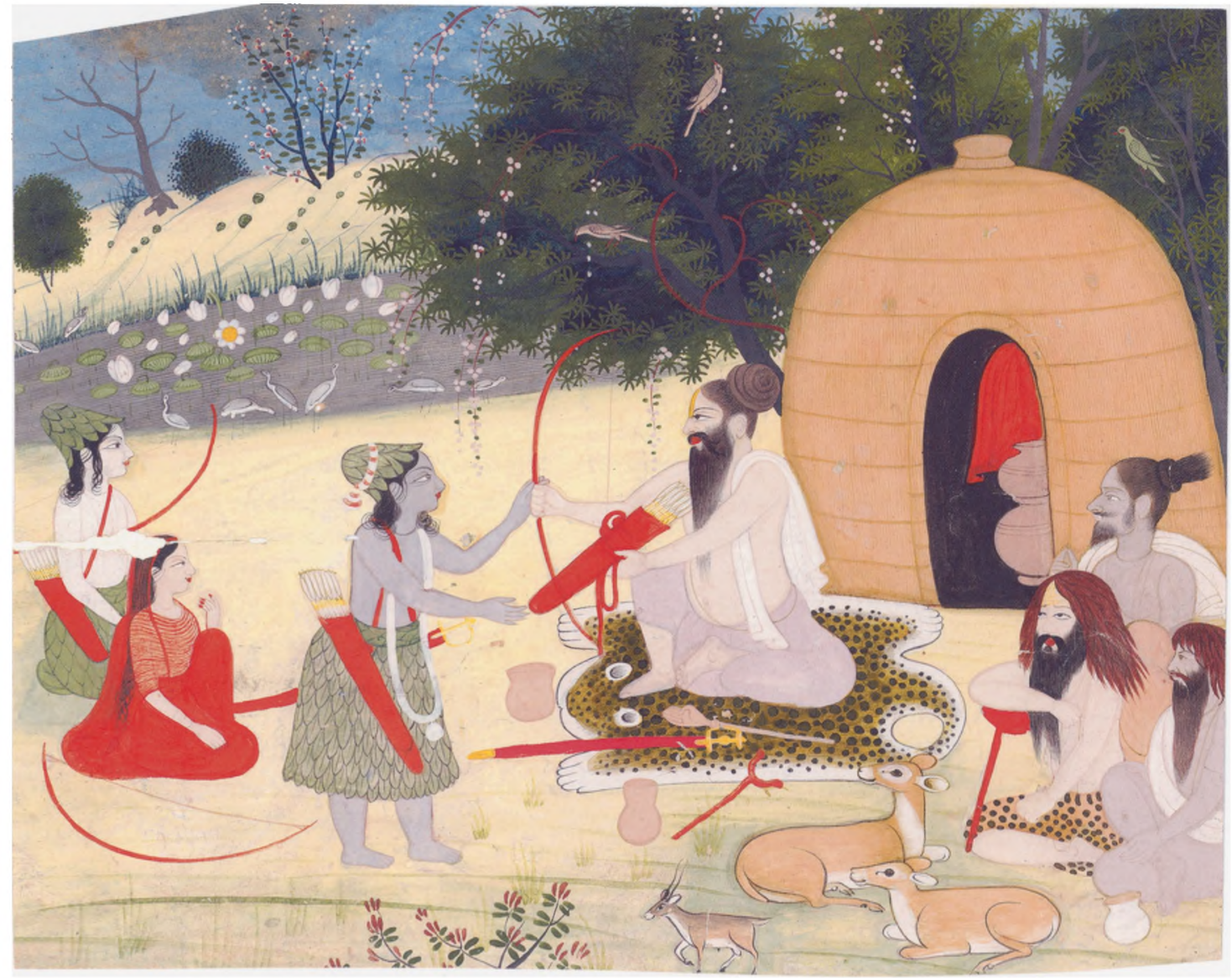

Figure 5

Sage Agastya's hermitage in the Vindhyan Mountains, parchment, $19.6 \mathrm{x}$ $25.0 \mathrm{~cm}$., Chamba, c. 1840, Museum Volkenkunde, 3025-20
Contrasting with the seemingly dry, mountainous abode of Bharadvaja, the hermitage of Agastya is shown in an idyllic, lush-green landscape (fig. 5). The peace and tranquillity of the ambience is accentuated by the blooming landscape studded with star-like flowers, which one also finds in Garhwal paintings. The lotus pond in he background is a common feature in both Garhwal and Kangra miniatures.

Certain elements in the illustration, such as the form of the leafy hats, the tigerskin seat on the ground and the figural forms, show unmistakable affinity to those seen in the Chamba paintings ranging in time from 1830 to $1850 .{ }^{10} \mathrm{On}$ the basis of such comparison one is entitled to date this particular miniature to circa 1840. Consequently, the series of Ramayana drawings in Leiden can be attributed to a period not earlier than 1790 and no later than 1840 .

With the beginning of Pahari paintings in the $17^{\text {th }}$ century, Ramayana proved to be an inexhaustible repertoire for court artists of various states in Himachal Pradesh. However, by the $19^{\text {th }}$ century, the Chamba-Kangra region exceeded others in visual rendering of the Rama legends. Of these two principalities it is more in Chamba that the cult of Rama enjoyed special veneration. Not only did the royal dynasty claim to have been descended from the epic hero, but Raghuvir ${ }^{11}$ was also the family deity of the ruling house of Chamba. 
Because of close geographical proximity and marriage alliance, there had been some mutually beneficial cultural exchanges between Chamba and Kangra. ${ }^{12}$ In all probabilities Chamba seems to have intensified the popularity of Ramayana in Kangra, a state where Bhagavata-Purana and lyricism of Krishna legends usually occupied pride of place. Kangra, the commonly acknowledged home of a highly sophisticated school of miniature paintings, it seems, exerted considerable influence on the style and technique of Chamba ateliers of the time. This is most evident in the few illustrations of the Ramayana episodes in the reserve collection of the National Museum of Ethnology in Leiden. ${ }^{13}$

\section{Notes}

1. A remarkable portrayal of Rama in early Indian Art is exemplified by the inscribed Gupta terracotta from Haryana, now in the Los Angeles County Museum of Art, published in P. Pal, Indian Sculpture. Vol. I, Los Angeles, 1986, p. 232. For a representative example of the popularity of the epic in South-East Asian Art, see the highly animated Ramayana reliefs in the Loro Jonggrang Temple in Indonesia, in A.J. Bernet Kempers, Ancient Indonesian Art, Amsterdam, 1959, pls. 153-54.

2. Besides the Ramayana themes, the Vogel collection of paintings in the museum consists of a wide range of subjects including Sikh portraits and pictures of birds and animals. None of these pieces measures more than $40 \mathrm{~cm}$. either in length or in breadth.

3. The results of Vogel's travail in these two valleys on both sides of the Dhauldhar Range are incorporated in several of his official publications, such as the Antiquities of Chamba State. Pt. I, Calcutta, 1911, and a number of illustrated articles in the Annual Report of the Archaeological Survey of India from 1902 to 1912.

4. For this and other episodes referred to in this paper, see a recent translation of the epic, H.P. Shastri, The Ramayana of Valmiki, London, 1992, 3 vols.

5. A brief discussion on the origin and usage of the Takri or Tankari script in the Western Himalayan territories can be found in J. Hutchison \& J.Ph. Vogel, History of the Panjab Hill States. Vol. I, Lahore, 1933, p. 269.

6. P. Banerjee, Rama in Indian Literature, Art and Thought. Vol. II, Delhi, 1986, pp. 2022.

7. A.C. Eastman,The Nala-Damayanti Drawings, Boston, 1959, pl. 2.

8. P. Pal, The Classical Tradition in Rajput Painting, New York, 1978, no. 78 on p. 207.

9. W.G. Archer, Visions of Courtly India, London/New York, 1976, no. 40 on p.73.

10. Ibid., Indian Paintings from the Punjab Hills, Vol. II, Delhi, 1973, pls. 53 and 58.

11. The word Raghuvir means the hero in the lineage of Raghu. It is an epithet of Rama.

12. For example, Raja Charat Singh (r. 1808-1844) had for his third wife a princess of Kangra. After the death of her husband this royal lady did not commit sati, but became the queen regent instead. There are two miniatures in the Chamba museum showing Charhat Singh and this queen in their pleasure garden in one, and watching the thunderstorm in the other. See J.Ph. Vogel, Catalogue of the Bhuri Singh Museum at Chamba, Calcutta, 1909, pp. 14 and 29.

13. I am thankful to Prof. Dr. Matthi Forrer, Head of the Research Section, Museum Volkenkunde in Leiden for permission to reproduce the photographs. I am also thankful to Dr.Ms. Nandana Chutiwongs, former curator of the South \& Southeast Asian section of the museum for providing me with all possible facilities to study this material in the reserve collection. 